\title{
Children and Adolexcents of Distinction - Culturally Diverse Children and Adolescents: Assessment, Diagnosis, and Treatment by lan A. Canino, M.D. and Jeanne Spurlock, M.D.
}

Lloyda R. Broomes M.D.

Follow this and additional works at: https://jdc.jefferson.edu/jeffjpsychiatry

Part of the Psychiatry Commons

Let us know how access to this document benefits you

\section{Recommended Citation}

Broomes, Lloyda R. M.D. (1996) "Children and Adolexcents of Distinction - Culturally Diverse Children and Adolescents: Assessment, Diagnosis, and Treatment by lan A. Canino, M.D. and Jeanne Spurlock, M.D.," Jefferson Journal of Psychiatry. Vol. 13 : Iss. 1 , Article 9.

DOI: https://doi.org/10.29046/JJP.013.1.009

Available at: https://jdc.jefferson.edu/jeffjpsychiatry/vol13/iss1/9

This Article is brought to you for free and open access by the Jefferson Digital Commons. The Jefferson Digital Commons is a service of Thomas Jefferson University's Center for Teaching and Learning (CTL). The Commons is a showcase for Jefferson books and journals, peer-reviewed scholarly publications, unique historical collections from the University archives, and teaching tools. The Jefferson Digital Commons allows researchers and interested readers anywhere in the world to learn about and keep up to date with Jefferson scholarship. This article has been accepted for inclusion in Jefferson Journal of Psychiatry by an authorized administrator of the Jefferson Digital Commons. For more information, please contact: JeffersonDigitalCommons@jefferson.edu. 


\title{
Book Reviews
}

\section{Children and Adolescents of Distinction}

\author{
CULTURALLY DIVERSE CHILDREN AND ADOLESCENTS: \\ ASSESSMENT, DIAGNOSIS, AND TREATMENT \\ Ian A. Canino, M.D. and Jeanne Spurlock, M.D. \\ The Guilford Press \\ 1994, Hardcover, 196 pp, $\$ 22.50$
}

\section{Lloyda R. Broomes, M.D.}

In the midst of an increasing sensitivity to the need for mental health clinicians to be adequately trained to work with children from diverse cultures, Ian Canino, M.D. and Jeanne Spurlock, M.D. wrote this volume. I eagerly purchased this book with the hope of developing an enhanced view of how to work with children of culturally diverse backgrounds, and I was not disappointed. The book focuses on four groups of children: African-American, Latino, Asian American, and Native American. One might see this as a limitation given the cultural diversity within these groups, as well as the diversity of other groups that are not mentioned. However, the general concepts presented can be applied to a wide range of culturally diverse children. Multiple case vignettes are used throughout the three sections of this book to illustrate techniques for obtaining histories, making diagnoses, and implementing interventions for minority youth. I found this to be one of the most valuable features of this book.

Section I opens with clarification of a few important concepts including ethnic diversity, ethnic socialization, ethnic development and ethnic identification. The authors emphasize that clinicians need to thoroughly understand the dimensions of ethnicity in order to diagnose and provide appropriate interventions for minority children. This section also includes a discussion of the impact of various social stressors on the mental health of minority children. For example, while discrimination is commonly observed as occurring between the majority and the minority cultures, it should also be noted that it is common to observe intraethnic discrimination among minority groups. Other minority children struggle with the process of acculturation or biculturalism as they are faced with a contradiction of the values of their culture and the dominant culture.

Careful attention must be given to the experiences faced by children who reside in inner cities as well as rural communities. Inner city children often face the limitation of overcrowded conditions and unsafe buildings. They may also attend 
schools that are without adequate supplies. Behavioral problems may develop in minority children as part of a downward cycle because of a learning disability or as a means to oppose the Anglo-American mainstream when they realistically perceive that African-Americans educational rewards lag behind those of Anglo-Americans. Other stressors reviewed included various environmental risk factors that often occur in minority children. Chronic poverty, family instability and a higher incidence of low birth weight infants are some of the factors that were mentioned. I was pleased to see that the authors also included a useful discussion on the importance of understanding the religion and the belief systems a child and his family follow. Belief systems vary within cultures and may affect assessment and treatment outcomes.

The authors were prudent to mention that protective factors have been identified in some minority children that enable them to become resilient. A positive sense of self, a sense of personal power and an internal locus of control have all been noted to be important characteristics that contribute to positive outcomes when a considerable amount of stress is present. I found the topic of protective factors to be an important issue, one I wish had been discussed in greater detail. This section ends with a summary on the correlation between psychiatric disorders and social class.

Section II focuses on the diagnostic challenge that mental health clinicians face when they must include the sociocultural factor. One chapter discusses the importance of cultural factors that affect the history that is obtained during an evaluation. The authors illustrate this by mentioning that a clinician may misunderstand belief systems of culture specific syndromes. One example is the syndrome Puerto Ricans refer to as "ataque," characterized by bizarre seizure patterns and violent behavior. The seizures are usually psychogenic in nature and the hallucinations that often occur may lead to a misdiagnosis of acute schizophreniform reaction or atypical psychosis. The history, including the attitudes of the family regarding health practices and child rearing practices, must be explored within the context of the child's environment. Additional family history that is often valuable includes knowledge of what community resources have been accessed, the role of extended family members, and what values the family holds as important.

The authors emphasize that culture can have an impact on the mental status exam as well. Minority children and their families may perceive contact with mental health professionals as a negative experience, and they may be uncomfortable with the process of a psychiatric exam. Body language and the use of non-standard English may become barriers to effective communication. An evaluation of the child's self-image must provide an opportunity for the child to voice how he perceives himself and with whom he identifies both inside and outside his family circle. The remaining chapters in this section focus on two concepts. First, clinicians conducting assessments must consider cultural biases of tests, as well as cultural factors, that may affect the outcome of those tests. Second, specific diagnostic categories, as described in DSM-IV, should be used with a particular concentration on sociocultural circumstances that may occur with minority children. Numerous appropriate examples are presented on how this can be accomplished.

The third and final section focuses on the treatment of minority children. 
Patterns have been observed regarding various cultural groups and their underutilization of mental health services. In order for this to improve, mental health services must be made available in ways that are more culturally sensitive. A clinician must also become more aware of the variable he contributes to the therapeutic process. Another valuable feature of this book is the broad range of treatment approaches that are presented, including non-traditional methods of providing services. The authors cite the use of folktales in group therapy as one non-traditional method that can be used to improve communication and transmit cultural values to children. The book concludes with a chapter that emphasizes that a mental health professional should be seen as an advocate for changes in both social policy and clinician training programs. But most of all, he should be seen as an advocate for children in prevention and early intervention.

In summary, this book challenges many misconceptions that have contributed to the misdiagnosis of minority children and adolescents in the past. It offers a review of how a clinician should approach the evaluation and therapeutic interaction with children of culturally diverse backgrounds. The authors provide an extensive list of references to which they refer throughout the text. I recommend that all mental health providers, especially psychiatry residents, read this book in order to heighten their clinical skills in working with children and adolescents of diverse cultures. 